\title{
Outcome of pregnancy in a contemporary cohort of adults with congenital heart disease-a 10-year, single-center experience
}

\author{
Betül Toprak $^{1} \wedge$, Katharina Govorov ${ }^{1}$, Katinka Kurz ${ }^{1}$, Dora Csengeri ${ }^{1}$, Jessica Weimann ${ }^{1}$, Dennis Witte ${ }^{1}$, \\ Kurt Hecher ${ }^{2}$, Bettina Hollwitz ${ }^{2}$, Anne Hansen ${ }^{1}$, Carsten Rickers ${ }^{3}$, Christina Magnussen ${ }^{1,4}$, \\ Yskert von Kodolitsch $^{1}$, Tanja Zeller ${ }^{1,4}$, Stefan Blankenberg ${ }^{1,4}$, Christoph Sinning ${ }^{1,3,4}$, Paulus Kirchhof ${ }^{1,4}$, \\ Elvin Zengin-Sahm ${ }^{1,3} \wedge$
}

\begin{abstract}
${ }^{1}$ Department of Cardiology, University Heart and Vascular Center Hamburg, University Medical Center Hamburg-Hospital Eppendorf, Hamburg, Germany; ${ }^{2}$ Department of Obstetrics and Fetal Medicine, University Medical Center Hamburg-Hospital Eppendorf, Hamburg, Germany; ${ }^{3}$ Adult Congenital Heart Disease Section, University Heart and Vascular Center Hamburg, University Medical Center Hamburg-Hospital Eppendorf, Hamburg, Germany; ${ }^{4}$ German Center for Cardiovascular Research (DZHK), Partner Site Hamburg/Kiel/Lübeck, Germany

Contributions: (I) Conception and design: C Sinning, E Zengin-Sahm; (II) Administrative support: Y von Kodolitsch; (III) Provision of study materials or patients: E Zengin-Sahm, C Sinning; (IV) Collection and assembly of data: B Toprak, K Govorov, D Witte; (V) Data analysis and interpretation: B Toprak, J Weimann, C Sinning, E Zengin-Sahm; (VI) Manuscript writing: All authors; (VII) Final approval of manuscript: All authors.

Correspondence to: Elvin Zengin-Sahm, MD. Department of Cardiology, University Heart and Vascular Center Hamburg, University Medical Center Hamburg-Hospital Eppendorf, 20246 Hamburg, Germany. Email: e.zengin@uke.de.
\end{abstract}

Background: Pregnancy may be associated with adverse outcome in women with congenital heart disease (CHD). However, data regarding the outcome of pregnancy in women with CHD who receive care in cardiac-obstetric expert units are limited.

Methods: We retrospectively analyzed baseline characteristics and outcome of pregnancy in 67 females with CHD who received medical care in our tertiary center for 61 singleton and 6 twin pregnancies between 2009 and 2018.

Results: According to the modified World Health Organization (mWHO) risk scale for pregnancy, CHD lesions in 39 enrolled women (58\%) were classified as mWHO class I or II, and in 28 females (42\%) as mWHO class III or IV. Preterm births were more frequent in $\mathrm{mWHO}$ classes III or IV $(\mathrm{P}=0.003)$. Cardiac signs and complications occurred more often in $\mathrm{mWHO}$ classes III or IV than in women with cardiac lesions assigned to $\mathrm{mWHO}$ classes I or II (42.9\% vs. $7.7 \%, \mathrm{P}=0.002)$. N-terminal pro B-type natriuretic peptide (NT-proBNP) levels during pregnancy were higher in $\mathrm{mWHO}$ classes III or IV than in $\mathrm{mWHO}$ classes I or II (median 269.0 vs. $115.5 \mathrm{pg} / \mathrm{mL}, \mathrm{P}=0.019)$. Presence of functional NYHA class III [odds ratio (OR) per standard deviation (SD) 8.8, 95\% confidence interval (CI): 2.2-57.2, P=0.008] and mWHO classes III/IV (OR per SD 3.4, 95\% CI: 1.2-9.9, $\mathrm{P}=0.018$ ) prior to pregnancy were identified as independent predictors of adverse cardiac outcome of pregnancy.

Conclusions: Adverse cardiac events and preterm deliveries should be anticipated in pregnant women with CHD, especially in those with mWHO classes III or IV. Therefore, these pregnancies should be under close surveillance and managed in specialized, multidisciplinary tertiary referral centers. Preconception counseling including individualized risk assessment is strongly recommended in women with CHD.

Keywords: Congenital heart disease (CHD); pregnancy; outcome

Submitted Jul 20, 2020. Accepted for publication Nov 30, 2020.

doi: $10.21037 / \mathrm{cdt}-20-650$

View this article at: http://dx.doi.org/10.21037/cdt-20-650

^ ORCID: Betül Toprak, 0000-0002-5233-0680; Christoph Sinning, 0000-0002-7331-8840; Elvin Zengin-Sahm, 0000-0001-5351-9162. 


\section{Introduction}

In women with congenital heart disease (CHD), pregnancy is a particularly multifaceted and challenging condition. Given the hemodynamic and hormonal changes during gestation (1-3), patients with CHD may face severe cardiovascular complications including heart failure, worsening of valve pathology and rhythm disorders $(1,4)$. Especially in adults with uncorrected, residual or complex CHD lesions, physiological hemodynamic adaptation mechanisms may lead to increasing circulatory instability during pregnancy (5). The presence of CHD is also known to predispose pregnant women and their unborn children to a variety of non-cardiac complications (1). However, most women with CHD seem to tolerate pregnancy without any difficulty and fetal outcome is favorable (6). Individualized risk stratification, ideally already done prior to conception, seems to be of paramount importance, in order to (I) identify patients with high-risk conditions and anticipate potentially lethal adverse events, and (II) relieve women who carry a low pregnancy-related risk $(7,8)$. In this context, the modified World Health Organization (mWHO) risk scale allows for a lesion-specific assignment of levels of risk to each woman regarding safety of pregnancy, and currently is considered to be the most accurate risk assessment tool (1). The individual risk ultimately determines the level of care during pregnancy (7). Due to the increasing number of women with complex CHD who reach a childbearing age and the consecutively growing complexity of maternal cardiac lesions $(9,10)$, guideline-based management by socalled "heart pregnancy teams" in tertiary care centers with pooled, multidisciplinary expertise substantially gains in importance (1). Although reports on the outcome of pregnancy in CHD are the basis for the optimal care of CHD patients during pregnancy and after delivery, studies yielding such data are scarce. Therefore, our study aims at providing further insights into the obstetric, fetal and cardiovascular outcome of pregnancy in women with CHD, and identifying patient characteristics which were associated with adverse cardiovascular outcome. We present the following article in accordance with the STROBE reporting checklist (available at http://dx.doi.org/10.21037/cdt-20-650).

\section{Methods}

For our retrospective, observational study we screened clinical records for females aged 18 years or older with known CHD. We identified a total of 67 females who presented to our joint cardiac-obstetric expert unit between October 2009 and December 2018 for prospective care during pregnancy. Data were retrospectively obtained from medical records as reported by qualified medical personnel. We documented the type of CHD and the respective $\mathrm{mWHO}$ class in each patient according to guideline-based criteria. If potentially adverse hemodynamic or rhythm features were present in addition to the CHD lesion, these conditions were also considered when determining the individual $\mathrm{mWHO}$ class which was then proofed by at least one cardiologist with special expertise in CHD (1). In patients with known complex CHD, we noted all relevant cardiac lesions, in order to map the full complexity of the individual cardiocirculatory condition. We assessed patient charts to record baseline data in all enrolled women. Baseline data included maternal age at delivery, body mass index (BMI), cardiovascular risk factors, implying arterial hypertension, smoking, diabetes and dyslipidemia, and the intake of medication, including angiotensin-converting enzyme inhibitors (ACEi), angiotensin-receptor blockers $(\mathrm{ARB})$ and $\beta$-adrenergic receptor blockers (BAB). To further characterize the maternal cardiovascular condition on a functional level, we documented the individual New York Heart Association (NYHA) class prior to index pregnancy. We also calculated the "CARdiac disease in PREGnancy" (CARPREG) cardiac risk score and assigned one point for each of the following risk criteria, if fulfilled: NYHA class III/IV or cyanosis, systemic ventricular ejection fraction below $40 \%$, left ventricular obstruction and prior cardiac event (11). If present, we gathered information on underlying syndromal diseases, heart failure, pulmonary hypertension, cyanotic lesions, patent shunts, and the surgical status of cardiac malformation prior to pregnancy. We defined familial predisposition as the presence of the same type of CHD in first-degree relatives. Besides the baseline data, obstetric, fetal and cardiovascular complications that occurred during pregnancy were documented. We noted information on pregnancy history, duration of index pregnancy, mode of delivery, indication for mode, and obstetric complications, which we defined as follows: gestational diabetes mellitus (GDM; any degree of glucose intolerance with onset or first recognition during pregnancy), preeclampsia (co-occurrence of pregnancyinduced hypertension and proteinuria $>0.3 \mathrm{~g}$ in a $24-\mathrm{h}$ urine sample), HELLP syndrome (hemolysis, elevated liver enzyme levels, and low platelet count during pregnancy), cervix insufficiency (inability of the uterine cervix to retain a pregnancy in the second trimester in the absence of 
clinical contractions, labor, or both), preterm premature rupture of membranes (PPROM, spontaneous rupture of membranes in the absence of regular painful contractions), protracted labor (abnormally slow cervical dilatation or fetal descent during active labor), and post-partum hemorrhage (blood loss $>500 \mathrm{~mL}$ at vaginal delivery or $>1,000 \mathrm{~mL}$ at Cesarean section). Fetal and neonatal outcome comprised preterm birth (delivery $<37$ weeks of gestation), intrauterine growth restriction (IUGR)/small for gestational age (SGA; fetal weight $<10^{\text {th }}$ percentile), abnormal amount of amniotic fluid, intrauterine death of fetus (fetal demise $>20$ weeks of gestation), and presence of CHD in fetus or neonate $(1,5)$. Cardiovascular outcome of index pregnancy implied any cardiac complication or symptom, including worsening or newly occurring symptoms of heart failure, echocardiographic signs of progressive valve dysfunction, pulmonary hypertension, volume overload or pregnancyrelated change of pressure conditions, and the need for percutaneous mechanical circulatory support. If available, we recorded the respective $\mathrm{N}$-terminal pro B-type natriuretic peptide (NT-proBNP) level measured before, during and within 1 year after pregnancy. We additionally noted the exact timing of measurement of NT-proBNP levels during pregnancy. In females with available data on post-partum follow-up visits, we documented the respective timing and recorded any cardiovascular complication that occurred within this follow-up period. Cardiovascular complications at post-partum follow-up comprised the occurrence of cardiac events, including arrhythmia, syncope, stroke and substantial worsening of valve dysfunction, as well as the need for percutaneous intervention, valve or aortic surgery. The study was conducted in accordance with the Declaration of Helsinki (as revised in 2013). The study was approved by the Ethics Board of Hamburg (PV 7124). Informed consent was not needed due to the purely retrospective nature of the study with anonymized analysis only of available medical records in our hospital information system.

\section{Statistical analysis}

We used bar graphs to illustrate the distribution and frequency of different CHD lesions and respective mWHO classes in our patient collective (Figure 1). For means of practicability, study participants were divided into two subgroups according to their assigned mWHO class; the first subgroup comprised mWHO classes I and II, and the second, mWHO classes III and IV. We screened for differences between these two mWHO clusters by using the Mann-Whitney $\mathrm{U}$ test for continuous data and the chi-square test for nominal and categorical data. Unless otherwise specified, median values with respective $25^{\text {th }}$ and $75^{\text {th }}$ percentiles were presented for continuous data, and absolute and relative frequencies were given for categorical data. Univariable logistic regression was conducted to identify patient characteristics associated with the occurrence of any cardiovascular complication during pregnancy. All variables with a $\mathrm{P}$ value $<0.25$ in univariable logistic regression were chosen for further selection methods because of their relevance in the univariable model. Afterwards, a backward subset selection was performed where the chosen method selected the model based on Akaike Information Criteria (AIC). To prepare the subset selection, variables with high amount of missing values or high correlation were excluded, in order to ensure a valid selection for multivariable logistic regression. Following variables were finally considered for subset selection: $\mathrm{mWHO}$ class, BMI, dyslipidemia, medication with BAB, NYHA class, CARPREG cardiac risk score, pulmonary hypertension, familial predisposition concerning CHD, gestational age at delivery and mode of childbirth. Both in univariable and multivariable models, presented coefficients show odds ratios (OR) with respective $95 \%$ confidence intervals (95\% CIs) for adverse pregnancyrelated cardiovascular outcome. Due to different units of the variables, the ORs are shown for an increase of one standard deviation (SD). For all analyses, a $\mathrm{P}$ value $<0.05$ was considered statistically significant. All statistical tests were performed using R Studio (Rstudio Team 2016; Rstudio: Integrated Development for R, Version 3.6.0. Boston, MA, USA: Rstudio Inc.).

\section{Results}

Among 67 patients with CHD, 39 females (58.2\%) with a median age of 31 years at delivery exhibited cardiac lesions according to $\mathrm{mWHO}$ class $\mathrm{I}(\mathrm{n}=10,14.9 \%)$ or II $(\mathrm{n}=29$, $43.3 \%$ ), and 28 women (41.8\%) with a median age of 29 years were classified as $\mathrm{mWHO}$ class III $(\mathrm{n}=20,29.9 \%)$ or IV $(\mathrm{n}=8,11.9 \%)$. The distribution and frequencies of CHD types are shown in Figure 1. The most frequent singlelesion CHD types were the tetralogy of Fallot (11.9\%), bicuspid aortic valve (BAV; 11.9\%) and ventricular septal defect (VSD; 9.0\%). Overall, also considering those lesions in complex, multi-lesion CHD, the most common congenital malformations were the following: VSD (13.2\%), coarctation of the aorta (COA; $11 \%)$ and patent ductus 


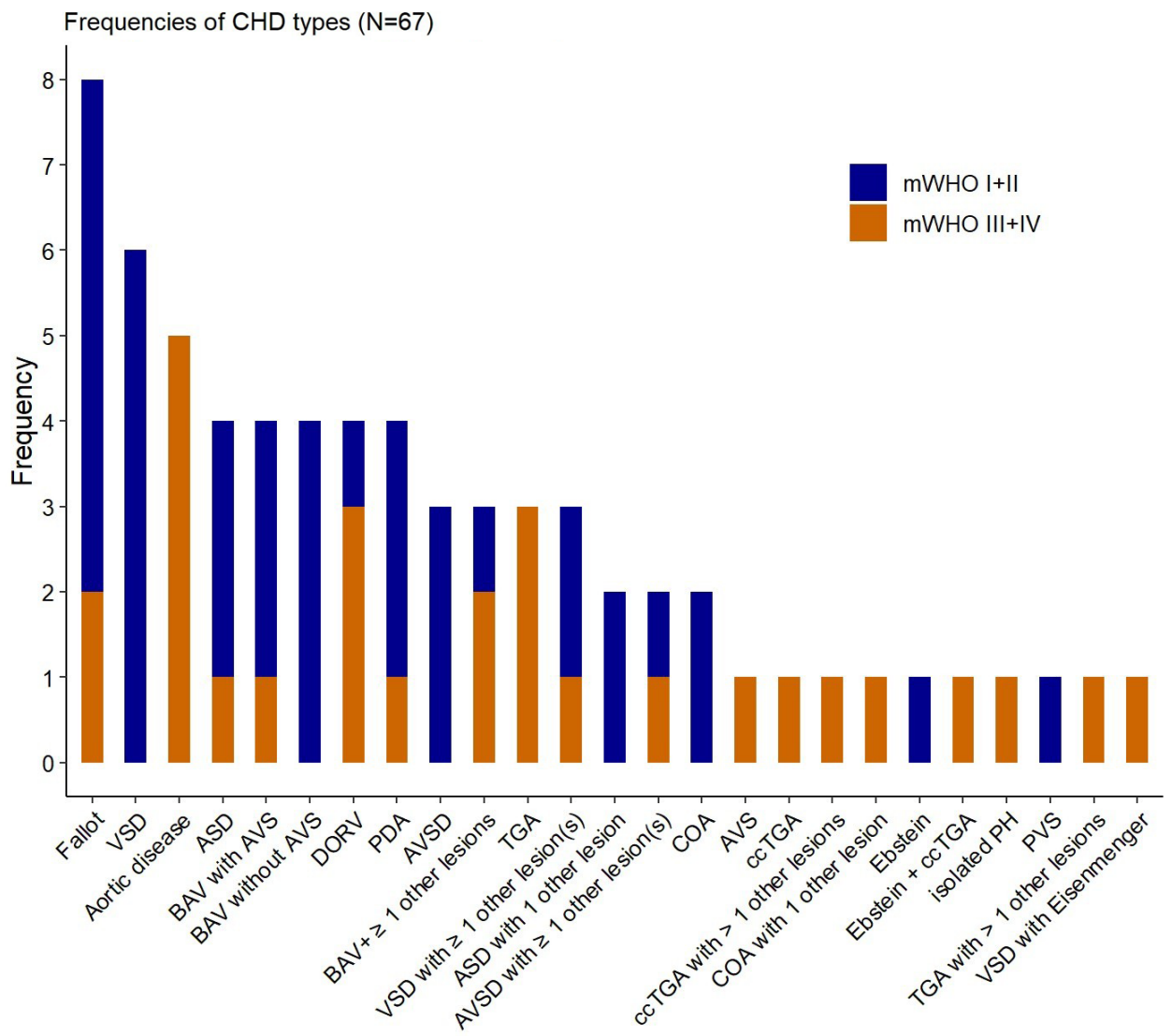

Figure 1 Distribution and frequency of CHD types in 67 females with CHD according to mWHO classes. One individual with repaired ASD was assigned to $\mathrm{mWHO}$ class III/IV because of previous resuscitation due to ventricular fibrillation and recurrent events of ventricular tachycardia. Another individual with unrepaired PDA was classified as mWHO class III/IV due to severe shunting with beginning dilatation of the left atrium and increase in pulmonary resistance. All 5 women with aortic disease were classified as mWHO class III/IV due to aortic dilatation $\geq 4 \mathrm{~cm}$ in 4 women and presence of vascular Ehlers-Danlos syndrome (vEDS) in one case. mWHO, modified World Health Organization; CHD, congenital heart disease; ASD, atrial septal defect; AVS, aortic valve stenosis; AVSD, atrioventricular septal defect; BAV, bicuspid aortic valve; ccTGA, congenitally corrected TGA; COA, Coarctation of the aorta; DORV, double-outlet right ventricle; PDA, patent ductus arteriosus; PH, pulmonary arterial hypertension; PVS, pulmonary valve stenosis; TGA, transposition of great arteries; VSD, ventricular septal defect.

arteriosus (PDA; 9.9\%). The proportion of corrected CHD lesions was comparable between $\mathrm{mWHO}$ classes I/II and III/IV (64.1\% vs. 71.4\%, $\mathrm{P}=0.710$; Table 1).

\section{Baseline characteristics}

The prevalence of cardiovascular risk factors was comparable between the two mWHO clusters. Prepregnancy drug therapy with ACEi or ARB $(\mathrm{P}=0.016)$ and $\beta$-blockers $(P=0.052)$ was more frequent among women assigned to $\mathrm{mWHO}$ classes III/IV. The latter also exhibited a higher functional NYHA class $(\mathrm{P}=0.023)$ prior to index pregnancy than those with $\mathrm{mWHO}$ classes I/ II who had functional NYHA class I in $89.7 \%$ of cases $(\mathrm{P}<0.001)$. Similarly, women with $\mathrm{mWHO}$ classes III/IV had a significantly higher CARPREG risk score than those with $\mathrm{mWHO}$ classes I/II. Syndromal disorders were more frequent among patients in the $\mathrm{mWHO}$ cluster comprising classes III/IV, although the difference was not statistically significant ( $17.9 \%$ vs. $2.6 \%, \mathrm{P}=0.084)$. Overall, Marfan syndrome (MFS) was the most common syndromal disease in the CHD collective with a frequency of $4.5 \%$. 
Table 1 Baseline characteristics prior to index pregnancy of 67 women with CHD according to mWHO classes

\begin{tabular}{|c|c|c|c|c|}
\hline Variable & Total $(\mathrm{N}=67)$ & mWHO class I/II $(\mathrm{N}=39)$ & mWHO class III/IV (N=28) & $\mathrm{P}$ \\
\hline Maternal age at delivery in years & $29.5(26.4,34.0)$ & $31.0(26.4,34.6)$ & $29.0(26.8,33.2)$ & 0.650 \\
\hline BMl in $\mathrm{kg} / \mathrm{m}^{2}$ & $23.3(20.4,25.1)$ & $22.7(20.0,24.8)$ & $23.7(21.6,26.2)$ & 0.200 \\
\hline Arterial hypertension & $10(14.9)$ & $4(10.3)$ & $6(21.4)$ & 0.360 \\
\hline Prior smoking & $5(7.5)$ & $3(7.7)$ & $2(7.1)$ & 1.000 \\
\hline \multicolumn{5}{|l|}{ Medication, n (\%) } \\
\hline ACEi/ARB & 8 (11.9) & $1(2.6)$ & $7(25.0)$ & $0.016^{*}$ \\
\hline BAB & $11(16.4)$ & $3(7.7)$ & $8(28.6)$ & 0.052 \\
\hline Aspirin & $6(9.0)$ & $4(10.3)$ & $2(7.1)$ & 0.990 \\
\hline \multicolumn{5}{|l|}{ Cardiovascular condition before pregnancy } \\
\hline \multicolumn{5}{|l|}{ NYHA classification', n (\%) } \\
\hline NYHA I & $45(71.4)$ & $35(89.7)$ & $10(41.7)$ & $<0.001^{*}$ \\
\hline NYHA II & $9(14.3)$ & $2(5.1)$ & $7(29.2)$ & $0.023^{*}$ \\
\hline NYHA III & $9(14.3)$ & $2(5.1)$ & $7(29.2)$ & $0.023^{*}$ \\
\hline NYHA IV & 0 & 0 & 0 & \\
\hline \multicolumn{5}{|l|}{ CARPREG cardiac risk score in points, $\mathrm{n}(\%)$} \\
\hline 0 & $45(67.2)$ & $34(87.2)$ & $11(39.3)$ & $<0.001^{\star}$ \\
\hline 1 & $16(23.9)$ & $4(10.3)$ & $12(42.9)$ & $0.005^{*}$ \\
\hline Re-surgery, n (\%) & $14(21.2)$ & $9(23.7)$ & $5(17.9)$ & 0.790 \\
\hline Cyanotic lesion, n (\%) & $1(1.5)$ & 0 & $1(3.6)$ & 0.870 \\
\hline Shunt, n (\%) & $11(16.4)$ & $6(15.4)$ & $5(17.9)$ & 1.000 \\
\hline Syndromal disease, n (\%) & $6(9.0)$ & $1(2.6)$ & 5 (17.9) & 0.084 \\
\hline $\mathrm{MFS}^{2}$ & $3(4.5)$ & 0 & $3(10.7)$ & 0.140 \\
\hline $\operatorname{LDS}^{2}$ & $1(1.5)$ & 0 & $1(3.6)$ & 0.870 \\
\hline Vascular EDS ${ }^{2}$ & $1(1.5)$ & 0 & $1(3.6)$ & 0.870 \\
\hline Trisomy 21 & $1(1.5)$ & $1(2.6)$ & 0 & 1.000 \\
\hline Familial predisposition concerning CHD, n (\%) & $4(6.0)$ & $1(2.6)$ & $3(10.7)$ & 0.390 \\
\hline
\end{tabular}

Characteristics were described by median values with $25^{\text {th }}, 75^{\text {th }}$ percentiles in parentheses for continuous variables and absolute numbers with relative percentages in parentheses for categorical variables. ${ }^{1}$, in medical records of 4 women, no NYHA class prior to index pregnancy was available; ${ }^{2}$, all 5 women with genetic aortopathies were classified as $\mathrm{mWHO}$ class III/IV either due to aortic root dilatation $>4 \mathrm{~cm}$ or presence of vascular EDS. *, P value <0.05. mWHO, modified World Health Organization; BMl, body mass index; ACEi, Angiotensin-converting enzyme inhibitor; ARB, angiotensin-receptor blocker; BAB, $\beta$-adrenergic receptor blocker; LMWH, low molecular weight heparin; NYHA, New York Heart Association; CARPREG, CARdiac disease in PREGnancy; MFS, Marfan syndrome; LDS, Loeys-Dietz syndrome; EDS, Ehlers-Danlos syndrome; $\mathrm{CHD}$, congenital heart disease. 


\section{Obstetric and fetal outcome of pregnancy}

A total of 61 singleton (91\%) and 6 twin pregnancies (9\%) were documented with similar distribution between the two $\mathrm{mWHO}$ clusters $(\mathrm{P}=0.390)$. Gestational age at delivery was lower in $\mathrm{mWHO}$ classes III/IV than in classes I/II (median 37.0 vs. 39.0 weeks of gestation, $\mathrm{P}<0.001)$. Subsequently, preterm birth occurred more often in women with $\mathrm{mWHO}$ risk classes III/IV (13.2\% vs. 50.0\%, $\mathrm{P}=0.003)$. Females with CHD assigned to $\mathrm{mWHO}$ classes III/IV gave birth by Cesarean section more frequently than those with $\mathrm{mWHO}$ classes I/II ( $85.7 \%$ vs. $55.3 \%, \mathrm{P}=0.018)$. A cardiac indication for Cesarean section was given in 7 females with $\mathrm{mWHO}$ classes III/IV and in 3 with $\mathrm{mWHO}$ classes I/II $(\mathrm{P}=0.440)$. In the latter, Cesarean section was performed because of mild bicuspid aortopathy, a high burden of ventricular ectopic beats in a patient with BAV, and hypoplasia of the pulmonary arterial system in a woman with corrected PDA and recurrent need for pulmonary dilatation. Overall, obstetric and fetal complications occurred with similar proportions in both mWHO clusters (Table 2).

\section{Cardiovascular outcome of pregnancy}

The prevalence of cardiovascular complications during pregnancy was higher in $\mathrm{mWHO}$ classes III/IV than in $\mathrm{mWHO}$ classes I/II (42.9\% vs. $7.7 \%, \mathrm{P}=0.002)$. One female with severe pulmonary hypertension $(1.5 \%)$ and a pre-pregnancy mWHO class IV had to be supported by extracorporeal membrane oxygenation (ECMO) due to acute on chronic right heart failure with consecutive multiple organ dysfunction at 24 weeks of gestation. Measurement of NT-proBNP levels during pregnancy (median 269.0 vs. $115.5 \mathrm{pg} / \mathrm{mL}, \mathrm{P}=0.019$ ) and in the postpartum period up to 12 months after delivery (median 308.0 vs. $71.0 \mathrm{pg} / \mathrm{mL}, \mathrm{P}<0.001$ ) yielded higher values in women assigned to $\mathrm{mWHO}$ risk classes III/IV than to $\mathrm{mWHO}$ classes I/II. Timing of measurement of NTproBNP levels during pregnancy was comparable (median 24.0 vs. 32.0, $\mathrm{P}=0.052$ ) between the $\mathrm{mWHO}$ clusters (Table 3). Multivariable logistic regression identified pre-pregnancy NYHA class III (OR per SD 8.8, 95\% CI: 2.2-57.2, P=0.008) and $\mathrm{mWHO}$ classes III/IV (OR per SD 3.4, 95\% CI: 1.2 9.9, $\mathrm{P}=0.018$ ) as independent predictors of cardiovascular complications during pregnancy (Table 4). During a median observation time of 214 days after delivery, cardiovascular complications occurred in $32 \%$ of women with $\mathrm{mWHO}$ classes III/IV as compared to $17.4 \%$ of females with
$\mathrm{mWHO}$ classes I/II ( $\mathrm{P}=0.400)$. Overall, the need for valve surgery $(8.3 \%)$ and the occurrence of arrhythmias including symptomatic supraventricular tachycardia, a high burden of ventricular ectopic beats with consecutive palpitations and an event of slow ventricular tachycardia with need for ablation therapy $(6.2 \%)$ were the most common cardiac complications that were observed during post-partum period. Among 4 individuals who underwent valve surgery or intervention after delivery, 1 patient developed a denovo and progressive mitral insufficiency during pregnancy, whereas 3 women with known valvular dysfunction of at least moderate degree developed symptoms of cardiac decompensation during pregnancy or delivery. Other post-partum cardiovascular complications comprised the following: syncope due to severe pulmonary hypertension, stroke by occlusion of the left middle cerebral artery 4 months after delivery, dilatation of the left pulmonary artery in a patient with known pulmonary hypoplasia, rapid worsening of mitral insufficiency from mild to severe within 1 week after delivery, and elective surgery of the proximal aorta in a woman with MFS before planned pregnancy (Table 3).

\section{Discussion}

Our retrospective, observational study of 67 pregnancies in women with CHD and with prospective care during pregnancy in our joint cardiac-obstetric unit identified a higher rate of cardiovascular complications in $\mathrm{mWHO}$ classes III/IV than in mWHO classes I/II. NT-proBNP levels measured during pregnancy and within 1 year after delivery were also higher in mWHO classes III/ IV. Multivariable logistic regression analysis indicated that the presence of pre-pregnancy NYHA class III and $\mathrm{mWHO}$ classes III/IV predisposed respective females to adverse cardiac events during pregnancy. Although preterm births occurred more frequently in $\mathrm{mWHO}$ classes III/ $\mathrm{IV}$, the overall prevalence of obstetric and fetal events was comparable between both $\mathrm{mWHO}$ clusters.

With an overall rate of approximately $13 \%$, VSD was the most common type of lesion in our CHD collective, which is in line with results derived from the "Registry of Pregnancy And Cardiac disease" (ROPAC) registry (12). In our study, patients with cardiac lesions assigned to $\mathrm{mWHO}$ risk classes III/IV had a worse functional NYHA class and higher CARPREG cardiac risk score prior to pregnancy than those with low- to intermediate-risk pregnancies according to $\mathrm{mWHO}$ classification. Premature births occurred in $50 \%$ of pregnancies in women with pre- 
Table 2 Obstetric and fetal outcome of index pregnancy in 67 women with CHD according to mWHO classes

\begin{tabular}{|c|c|c|c|c|}
\hline Variable & Total $(\mathrm{N}=67)$ & mWHO class I/II (N=39) & mWHO class III/IV (N=28) & $P$ \\
\hline Number of previous births & $0(0,1.0)$ & $0(0,1.0)$ & $0(0,1.0)$ & 0.800 \\
\hline Gestational age at delivery in weeks & $39.0(36.2,40.0)$ & $39.0(38.0,40.6)$ & $37.0(33.0,39.0)$ & $<0.001^{*}$ \\
\hline Preterm birth, $\mathrm{n}(\%)$ & $18(28.1)$ & $5(13.2)$ & $13(50.0)$ & $0.003^{*}$ \\
\hline Due to previous Cesarean section & $4(8.9)$ & $3(14.3)$ & $1(4.2)$ & 0.510 \\
\hline Cardiac reason & $10(22.2)$ & $3(14.3)$ & $7(29.2)$ & 0.440 \\
\hline Obstetric/fetal reason & $15(33.3)$ & $9(42.9)$ & $6(25.0)$ & 0.340 \\
\hline Both indications & $7(15.6)$ & 0 & $7(29.2)$ & $0.023^{*}$ \\
\hline \multicolumn{5}{|l|}{ Obstetric outcome of index pregnancy } \\
\hline Any complication/symptom, n (\%) & $25(37.3)$ & $15(38.5)$ & $10(35.7)$ & 1.000 \\
\hline GDM & $5(7.5)$ & $3(7.7)$ & $2(7.1)$ & \\
\hline Preeclampsia or HELLP syndrome & $4(6.0)$ & $3(7.7)$ & $1(3.6)$ & \\
\hline Cervix insufficiency & $4(6.0)$ & $3(7.7)$ & $1(3.6)$ & \\
\hline PPROM or preterm contractions & $8(11.9)$ & $4(10.3)$ & $4(14.3)$ & \\
\hline Protracted labor & $2(3.0)$ & $1(2.6)$ & $1(3.6)$ & \\
\hline Perineal tear & $1(1.5)$ & $1(2.6)$ & 0 & \\
\hline Polyhydramnios & $2(3.0)$ & $2(5.1)$ & 0 & \\
\hline Intrauterine death & $3(4.5)$ & $1(2.6)$ & $2(7.1)$ & \\
\hline $\mathrm{CHD}$ in fetus/neonate & $3(4.5)$ & $3(7.7)$ & 0 & \\
\hline
\end{tabular}

Characteristics were described by median values with $25^{\text {th }}, 75^{\text {th }}$ percentiles in parentheses for continuous variables and absolute numbers with relative percentages in parentheses for categorical variables. ${ }^{1}$, relative proportions of indications for Cesarean section are based on the total number of performed Cesarean sections. *, P value $<0.05$. CHD identifies congenital heart disease; mWHO, modified World Health Organization; GDM, gestational diabetes mellitus; HELLP, hemolysis, elevated liver enzymes, low platelet count; PPROM, preterm premature rupture of membranes; PPH, postpartum hemorrhage; IUGR, intrauterine growth restriction; N, number of patients; SGA, small for gestational age. 
Table 3 Cardiovascular outcome in 67 women with CHD according to $\mathrm{mWHO}$ classes

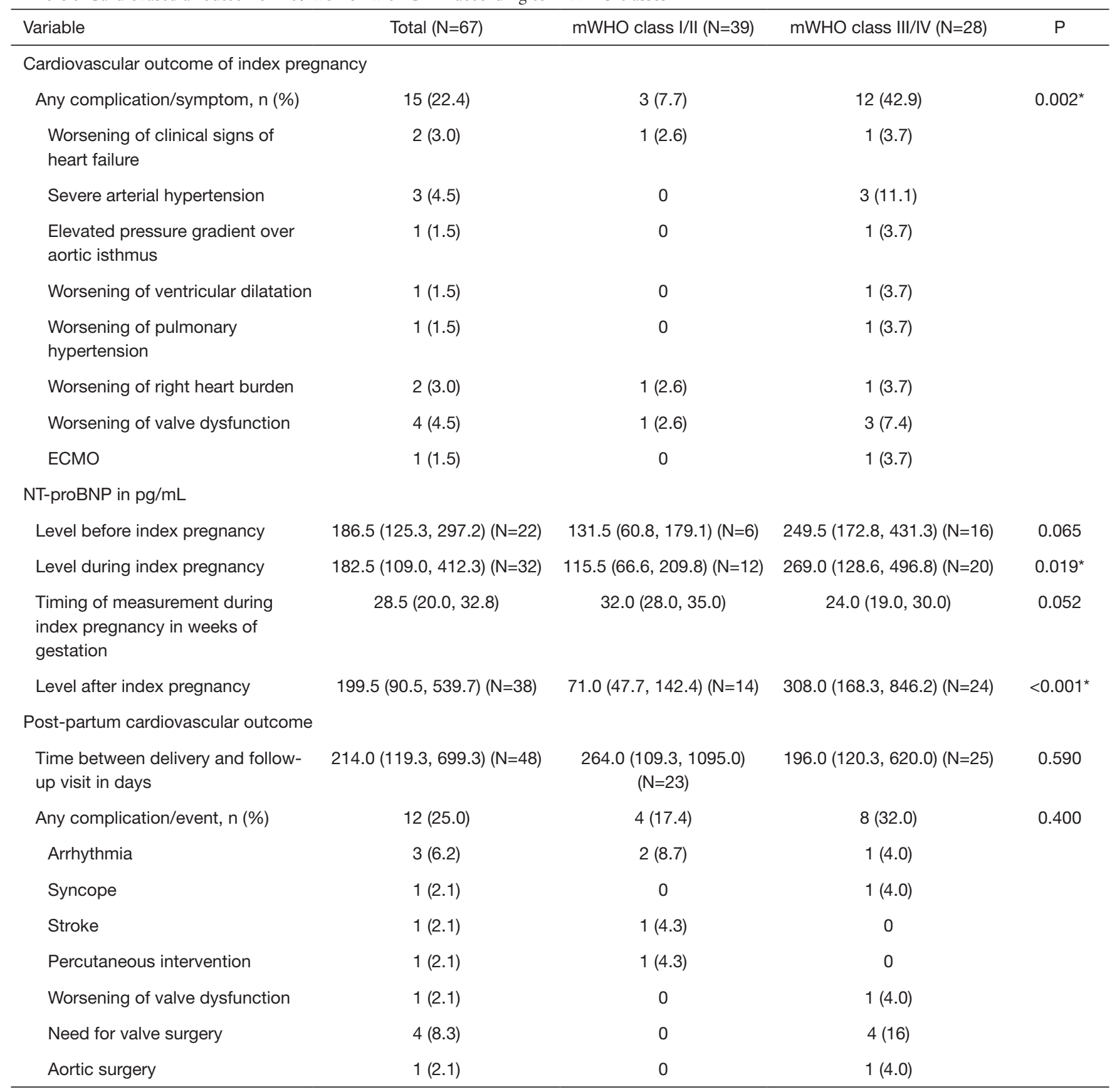

Characteristics were described by median values with $25^{\text {th }}, 75^{\text {th }}$ percentiles in parentheses for continuous variables and absolute numbers with relative percentages in parentheses for categorical variables. ${ }^{*}$, P value $<0.05$. CHD, congenital heart disease; mWHO, modified World Health Organization; ECMO, extracorporeal membrane oxygenation; NT-proBNP, N-terminal pro B-type natriuretic peptide. 
Table 4 Results of univariable and multivariable logistic regression for cardiovascular outcome of index pregnancy in 67 women with CHD

\begin{tabular}{|c|c|c|}
\hline Variable & OR per SD $(95 \% \mathrm{Cl})$ & $\mathrm{P}$ \\
\hline \multicolumn{3}{|l|}{ Univariable logistic regression } \\
\hline $\begin{array}{l}\text { Maternal age at delivery in } \\
\text { years }\end{array}$ & $1.25(0.70,2.22)$ & 0.420 \\
\hline $\mathrm{BMI}$ in $\mathrm{kg} / \mathrm{m}^{2}$ & $1.71(0.98,3.14)$ & 0.064 \\
\hline Arterial hypertension & $1.19(0.66,1.99)$ & 0.530 \\
\hline Prior smoking & $1.28(0.73,2.11)$ & 0.340 \\
\hline Dyslipidemia & $1.54(0.93,2.94)$ & 0.100 \\
\hline ACEi/ARB & $1.06(0.55,1.78)$ & 0.850 \\
\hline $\mathrm{BAB}$ & $1.37(0.79,2.30)$ & 0.230 \\
\hline Aspirin & $0.89(0.38,1.55)$ & 0.730 \\
\hline LMWH & $1.13(0.59,1.87)$ & 0.650 \\
\hline Methyldopa during pregnancy & $1.13(0.59,1.87)$ & 0.650 \\
\hline Number of pregnancies & $0.77(0.34,1.40)$ & 0.450 \\
\hline Number of previous births & $1.06(0.56,1.62)$ & 0.840 \\
\hline mWHO class III/IV & $2.98(1.57,6.53)$ & $0.002^{*}$ \\
\hline \multicolumn{3}{|l|}{ NYHA class } \\
\hline I & 1 (reference) & \\
\hline II & $1.34(0.65,2.49)$ & 0.370 \\
\hline III & $3.24(1.79,6.80)$ & $<0.001^{*}$ \\
\hline \multicolumn{3}{|l|}{ CARPREG risk score } \\
\hline 0 & 1 (reference) & \\
\hline 1 & $1.29(0.69,2.33)$ & 0.400 \\
\hline$>1$ & $1.99(1.18,3.65)$ & $0.013^{*}$ \\
\hline $\begin{array}{l}\text { NT-proBNP in } \mathrm{pg} / \mathrm{mL} \text { before } \\
\text { pregnancy }\end{array}$ & $0.98(0.15,2.52)$ & 0.960 \\
\hline $\begin{array}{l}\text { NT-proBNP in } \mathrm{pg} / \mathrm{mL} \text { during } \\
\text { pregnancy }\end{array}$ & $1.69(0.79,5.35)$ & 0.240 \\
\hline $\begin{array}{l}\text { NT-proBNP in } \mathrm{pg} / \mathrm{mL} \text { after } \\
\text { pregnancy }\end{array}$ & $4.62(1.19,119.67)$ & 0.240 \\
\hline $\begin{array}{l}\text { Peripheral oxygen saturation in } \\
\%\end{array}$ & $0.91(0.53,1.82)$ & 0.750 \\
\hline Heart failure & $1.19(0.66,1.97)$ & 0.510 \\
\hline Pulmonary hypertension & $1.89(1.14,3.42)$ & 0.017 \\
\hline Corrective surgery & $0.99(0.56,1.81)$ & 0.960 \\
\hline
\end{tabular}

Table 4 (continued)

\begin{tabular}{|c|c|c|}
\hline Variable & OR per SD $(95 \% \mathrm{Cl})$ & $P$ \\
\hline Re-surgery & $0.96(0.50,1.68)$ & 0.900 \\
\hline Shunt & $1.13(0.61,1.91)$ & 0.670 \\
\hline MFS & $1.14(0.59,1.88)$ & 0.630 \\
\hline Familial predisposition & $1.38(0.82,2.33)$ & 0.200 \\
\hline $\begin{array}{l}\text { Gestational age at delivery in } \\
\text { weeks }\end{array}$ & $0.66(0.33,1.14)$ & 0.160 \\
\hline Preterm birth & $1.76(1.03,3.29)$ & 0.050 \\
\hline \multicolumn{3}{|l|}{ Multivariable logistic regression } \\
\hline $\mathrm{BMl}$ in $\mathrm{kg} / \mathrm{m}^{2}$ & $2.3(1.0,6.7)$ & 0.067 \\
\hline Dyslipidemia & $1.4(0.7,2.9)$ & 0.280 \\
\hline \multicolumn{3}{|l|}{ CARPREG risk score } \\
\hline 0 & 1 (reference) & \\
\hline 1 & $0.2(0.0,0.8)$ & 0.067 \\
\hline$>1$ & $0.4(0.1,1.2)$ & 0.280 \\
\hline \multicolumn{3}{|l|}{ NYHA class } \\
\hline I & 1 (reference) & \\
\hline II & $2.1(0.7,7.3)$ & 0.230 \\
\hline III & $8.8(2.2,57.2)$ & $0.008^{*}$ \\
\hline $\mathrm{mWHO}$ class III/IV & $3.4(1.2,9.9)$ & $0.018^{*}$ \\
\hline
\end{tabular}

Due to different units of the variables, the ORs are shown for an increase of one standard deviation (SD). *, $\mathrm{P}$ value $<0.05$. $\mathrm{CHD}$, congenital heart disease; BMI, body mass index; $\mathrm{ACEi}$, angiotensin-converting enzyme inhibitor; $A R B$, angiotensinreceptor blocker; BAB, $\beta$-adrenergic receptor blocker; $\mathrm{LMWH}$, low molecular weight heparin; mWHO, modified World Health Organization; NYHA, New York Heart Association; CARPREG, CARdiac disease in PREGnancy; NT-proBNP, N-terminal pro B-type natriuretic peptide; MFS, Marfan syndrome; OR, odds ratio; $\mathrm{Cl}$, confidence interval.

Table 4 (continued) 
pregnancy $\mathrm{mWHO}$ classes III/IV. This finding may be in part explained by the immensely high rate of performed Cesarean sections in this high-risk collective. However, besides probable iatrogenic effects, it is important to note that PPROM and premature contractions were the most common obstetric complications in our CHD collective. Prematurity has also been identified as a common complication in women with severe cardiovascular compromise in previous studies $(4,5)$. Furthermore, IUGR occurred in almost one-third of all pregnancies in our CHD collective and was the most common fetal complication in our study as well as in previous investigations $(4,5)$. Placental insufficiency is known to play a pivotal role in the pathophysiology of IUGR and to occur more often in patients with severe cardiovascular conditions (4). The higher rate of IUGR in our CHD collective may therefore be due to the higher proportion of women with complex $\mathrm{CHD}$ who received care in our tertiary referral center. Vice versa, the lower proportion of very low-risk lesions which are known to carry a substantially lower risk for IUGR and were assigned to $\mathrm{mWHO}$ class I (25.6\%) within the $\mathrm{mWHO}$ cluster that also comprises $\mathrm{mWHO}$ class II $(74.4 \%)$ might be the explanation for comparable IUGR rates between $\mathrm{mWHO}$ cluster I/II and III/IV in our study.

In general, the presence of CHD is known to predispose to a variety of non-cardiac complications, including obstetric and fetal or neonatal complications $(1,5,13)$. Adverse obstetric and fetal outcomes were previously found to be associated with a higher $\mathrm{mWHO}$ class (12). However, we detected similar complications rates in $\mathrm{mWHO}$ classes III/IV as compared to mWHO classes I/II. Although a variety of distinct predictors for adverse obstetric and fetal outcome in CHD have been identified $(5,11,14)$, no validated risk prediction models exist to date (1). Cardiac symptoms or complications were more likely to occur in $\mathrm{mWHO}$ classes III/IV, and the presence of one of these two classes was identified as an independent predictor of adverse cardiac outcome of index pregnancy in our study. Our findings underscore the importance of the $\mathrm{mWHO}$ risk classification tool as an indispensable cornerstone of preconception counseling $(1,12,15-19)$. Previous investigations also showed that increased NT-proBNP levels may predict cardiovascular events during pregnancy in CHD $(20,21)$. In fact, elevated NT-proBNP levels during pregnancy may indicate insufficient volume and/or pressure adaptations of the cardiovascular system $(1,6)$, and thus serve as a valuable biomarker for the estimation of pregnancy-related risk in CHD. Although NT-proBNP levels were higher in
$\mathrm{mWHO}$ classes III/IV, univariable logistic regression did not identify NT-proBNP as a potential predictor of adverse cardiovascular outcome in our study. Therefore, largescale studies are needed to explore the full potential for the use of NT-proBNP in pregnant patients with CHD. During post-partum observation, one fourth of all women experienced cardiovascular complications, among which the need for valve surgery (8.3\%) and arrhythmia (6.2\%) were the most commonly reported adverse events. As some of the conditions that led to cardiac surgery already existed before pregnancy, our explorative study does not prove any causative correlation between a previously completed pregnancy and cardiovascular events. However, previous studies similarly indicated a possible association between previous pregnancy and cardiac events in the long term; one study even reported an increased risk of late cardiac events within a median of 2.6 years after pregnancy (22). Close cardiac follow-up in the post-partum period is therefore warranted in patients with CHD and further confirmatory data is needed.

\section{Limitations}

Given the limited sample size of our study, statistics have to be considered with caution and were therefore mainly designed in a descriptive manner. Considering the retrospective design of our study, missing or incomplete data were inevitable and underreporting may be a limiting factor as only documented complications were included. Due to the heterogeneous variety of lesions within our CHD cohort, lesion-specific results cannot be drawn from these data. In fact, the present cohort is representative for a CHD collective receiving medical care in a specialized university expert unit and caution may be warranted when extrapolating these results to other CHD populations outside a tertiary care setting.

\section{Conclusions}

Adverse cardiac events and preterm deliveries should be anticipated in pregnant women with CHD, especially in those with mWHO classes III or IV. Therefore, these pregnancies should be under close surveillance and managed in specialized, multidisciplinary tertiary referral centers. Preconception counseling including individualized risk assessment is warranted in women with CHD. Large multicenter studies, ideally of prospective design, are necessary to further elucidate the outcome of pregnancy 
in CHD, identify predictors of adverse pregnancy-related events, and subsequently optimize cardiac-obstetric management of pregnancy in CHD by implementing newly gained knowledge into the real-world care setting.

\section{Acknowledgments}

Funding: None.

\section{Footnote}

Provenance and Peer Review: This article was commissioned by the editorial office, Cardiovascular Diagnosis and Therapy for the series "Current Management Aspects in Adult Congenital Heart Disease (ACHD): Part IV". The article has undergone external peer review.

Reporting Checklist: The authors have completed the STROBE reporting checklist. Available at http://dx.doi. org/10.21037/cdt-20-650

Data Sharing Statement: Available at http://dx.doi. org/10.21037/cdt-20-650

Conflicts of Interest: All authors have completed the ICMJE uniform disclosure form (available at http:// dx.doi.org/10.21037/cdt-20-650). The series "Current Management Aspects in Adult Congenital Heart Disease (ACHD): Part IV" was commissioned by the editorial office without any funding or sponsorship. YvK serves as an unpaid editorial board member of Cardiovascular Diagnosis and Therapy from February 2018 to January 2022 and served as the unpaid Guest Editor of the series. Dr. SB reports grants and personal fees from Abbott Diagnostics, grants and personal fees from Bayer, grants from SIEMENS, grants from Singulex, grants and personal fees from Thermo Fisher, personal fees from Abott, personal fees from Astra Zeneca, personal fees from AMGEN, personal fees from Medtronic, personal fees from Pfizer, personal fees from Roche, personal fees from Novartis, personal fees from Siemens Diagnostics, outside the submitted work; Dr. PK reports non-financial support from the European Union, British Heart Foundation, Leducq Foundation, Medical Research Council (UK), and German Centre for Heart Research, outside the submitted work; In addition, Dr. PK is listed as inventor on two patents held by University of Birmingham (Atrial Fibrillation Therapy WO 2015140571, Markers for Atrial Fibrillation WO 2016012783). He received research support for basic, translational and clinical research projects from several drug and device companies active in atrial fibrillation, and has received honoraria from several such companies in the past, but not in the last 3 years. The authors have no other conflicts of interest to declare.

Ethical Statement: The authors are accountable for all aspects of the work in ensuring that questions related to the accuracy or integrity of any part of the work are appropriately investigated and resolved. The study was conducted in accordance with the Declaration of Helsinki (as revised in 2013). The study was approved by the Ethics Board of Hamburg (PV 7124). Informed consent was not needed due to the purely retrospective nature of the study with anonymized analysis only of available medical records in our hospital information system.

Open Access Statement: This is an Open Access article distributed in accordance with the Creative Commons Attribution-NonCommercial-NoDerivs 4.0 International License (CC BY-NC-ND 4.0), which permits the noncommercial replication and distribution of the article with the strict proviso that no changes or edits are made and the original work is properly cited (including links to both the formal publication through the relevant DOI and the license). See: https://creativecommons.org/licenses/by-nc-nd/4.0/.

\section{References}

1. Regitz-Zagrosek V, Roos-Hesselink JW, Bauersachs J, et al. 2018 ESC Guidelines for the management of cardiovascular diseases during pregnancy. Eur Heart J 2018;39:3165-241.

2. Manalo-Estrella P, Barker AE. Histopathologic findings in human aortic media associated with pregnancy. Arch Pathol 1967;83:336-41.

3. Kampman MA, Valente MA, van Melle JP, et al. Cardiac adaption during pregnancy in women with congenital heart disease and healthy women. Heart 2016;102:1302-8.

4. Drenthen W, Pieper PG, Roos-Hesselink JW, et al. Outcome of pregnancy in women with congenital heart disease: a literature review. J Am Coll Cardiol 2007;49:2303-11.

5. Drenthen W, Boersma E, Balci A, et al. Predictors of pregnancy complications in women with congenital heart disease. Eur Heart J 2010;31:2124-32.

6. Zengin E, Mueller G, Blankenberg S, et al. Pregnancy in 
adults with congenital heart disease. Cardiovasc Diagn Ther 2019;9:S416-S423.

7. Roos-Hesselink JW, Budts W, Walker F, et al. Organisation of care for pregnancy in patients with congenital heart disease. Heart 2017;103:1854-9.

8. Greutmann M, Pieper PG. Pregnancy in women with congenital heart disease. Eur Heart J 2015;36:2491-9.

9. Elkayam U, Goland S, Pieper PG, et al. High-Risk Cardiac Disease in Pregnancy: Part I. J Am Coll Cardiol 2016;68:396-410.

10. Marelli AJ, Mackie AS, Ionescu-Ittu R, et al. Congenital heart disease in the general population: changing prevalence and age distribution. Circulation 2007;115:163-72.

11. Siu SC, Sermer M, Colman JM, et al. Prospective multicenter study of pregnancy outcomes in women with heart disease. Circulation 2001;104:515-21.

12. Roos-Hesselink JW, Ruys TP, Stein JI, et al. Outcome of pregnancy in patients with structural or ischaemic heart disease: results of a registry of the European Society of Cardiology. Eur Heart J 2013;34:657-65.

13. Hrycyk J, Kaemmerer H, Nagdyman N, et al. Mode of Delivery and Pregnancy Outcome in Women with Congenital Heart Disease. PLoS One 2016;11:e0167820.

14. Presbitero P, Somerville J, Stone S, et al. Pregnancy in cyanotic congenital heart disease. Outcome of mother and fetus. Circulation 1994;89:2673-6.

15. Cauldwell M, Gatzoulis M, Steer P. Congenital heart disease and pregnancy: A contemporary approach to

Cite this article as: Toprak B, Govorov K, Kurz K, Csengeri D, Weimann J, Witte D, Hecher K, Hollwitz B, Hansen A, Rickers C, Magnussen C, von Kodolitsch Y, Zeller T, Blankenberg S, Sinning C, Kirchhof P, Zengin-Sahm E. Outcome of pregnancy in a contemporary cohort of adults with congenital heart diseasea 10-year, single-center experience. Cardiovasc Diagn Ther 2021;11(6):1344-1355. doi: 10.21037/cdt-20-650 counselling, pre-pregnancy investigations and the impact of pregnancy on heart function. Obstet Med 2017;10:53-7.

16. Canobbio MM, Warnes CA, Aboulhosn J, et al. Management of Pregnancy in Patients With Complex Congenital Heart Disease: A Scientific Statement for Healthcare Professionals From the American Heart Association. Circulation 2017;135:e50-87.

17. Cauldwell M, Ghonim S, Uebing A, et al. Preconception counseling, predicting risk and outcomes in women with $\mathrm{mWHO} 3$ and 4 heart disease. Int J Cardiol 2017;234:76-80.

18. Pijuan-Domènech $\mathrm{A}$, Galian L, Goya $\mathrm{M}$, et al. Cardiac complications during pregnancy are better predicted with the modified WHO risk score. Int J Cardiol 2015;195:149-54.

19. van Hagen IM, Boersma E, Johnson MR, et al. Global cardiac risk assessment in the Registry Of Pregnancy And Cardiac disease: results of a registry from the European Society of Cardiology. Eur J Heart Fail 2016;18:523-33.

20. Kampman MA, Balci A, van Veldhuisen DJ, et al. $\mathrm{N}$-terminal pro-B-type natriuretic peptide predicts cardiovascular complications in pregnant women with congenital heart disease. Eur Heart J 2014;35:708-15.

21. Tanous D, Siu SC, Mason J, et al. B-type natriuretic peptide in pregnant women with heart disease. J Am Coll Cardiol 2010;56:1247-53.

22. Balint OH, Siu SC, Mason J, et al. Cardiac outcomes after pregnancy in women with congenital heart disease. Heart 2010;96:1656-61. 